\title{
Treatment of sclerosing mesenteritis with corticosteroids and azathioprine
}

\author{
Anand Bala MD FRCPC, Sylvain P Coderre MD FRCPC, Douglas RE Johnson MD FRCS, V Nayak MD FRCS
}

\begin{abstract}
A Bala, SP Coderre, DRE Johnson, V Nayak. Treatment of sclerosing mesenteritis with corticosteroids and azathioprine. Can J Gastroenterol 2001;15(8):533-535. Sclerosing (idiopathic) mesenteritis is a rare disease that may present with abdominal pain or bowel obstruction. A 21-year-old man was diagnosed with sclerosing mesenteritis, and treated with a partial ileal resection and defunctioning ileostomy. He was subsequently started on corticosteroids and azathioprine. Five months later, at the time of ileostomy reversal, he was disease-free. The diagnosis and management of this disease are discussed.
\end{abstract}

Key Words: Abdominal pain; Bowel obstruction; Sclerosing mesenteritis

\section{Traitement de la mésentérite sclérosante à l'aide de corticostéroïdes et d'azathioprine}

RÉSUMÉ : La mésentérite sclérosante, d'origine idiopathique, est une maladie rare qui peut se manifester sous forme de douleurs abdominales ou d'obstruction intestinale. Voici le cas d'un homme de 21 ans chez qui une mésentérite sclérosante a été diagnostiquée; il a subi une résection partielle de l'iléon et une iléostomie temporaire. On a ensuite amorcé un traitement aux corticostéroïdes et à l'azathioprine. Cinq mois plus tard, au moment où l'on a procédé à la fermeture de l'iléostomie, il était complètement guéri. Suit dans le présent article une discussion sur le diagnostic et le traitement de la maladie.
Cclerosing mesenteritis (also known as idiopathic mesen$\checkmark$ teritis, retractile mesenteritis, liposclerotic mesenteritis) is a very uncommon, benign process that usually involves the small bowel (1). Nonspecific inflammation and progressive fibrosis infiltrate, thicken and retract the mesentery, which may lead to a number of gastrointestinal symptoms, including abdominal pain and bowel obstruction. The etiology and pathogenesis of this disorder are unknown. A patient with histologically proven sclerosing mesenteritis who presented with abdominal pain and incomplete small bowel obstruction is described. The patient was treated successfully with surgery, corticosteroids and azathioprine.

\section{CASE PRESENTATION}

A 21-year-old white man was admitted with a $24 \mathrm{~h}$ history of progressive right lower quadrant abdominal pain. Nausea and vomiting began after the onset of the pain. There were no significant changes in bowel habit. He denied weight loss, night sweats or fever. There was no history of recent travel or infectious contacts. His past medical, social and family histories were unremarkable. He was not on any medications. Physical examination revealed a toxic-appearing man with tachycardia but who was afebrile. The abdomen was soft, with localized guarding and rebound in the right lower quadrant. No masses were palpable, bowel sounds were absent and results of a rectal examination were normal. The

Divisions of Gastroenterology and General Surgery, and Department of Pathology, Peter Lougheed Hospital, University of Calgary, Calgary, Alberta Correspondence: Dr Sylvain P Coderre, Division of Gastroenterology, Peter Lougheed Hospital, 3500-26th Street Northeast, Calgary,

Alberta T1Y 6J4. Telephone 403-219-1512, fax 403-291-8017, e-mail sylvain.coderre@CRHA-Health.Ab.Ca

Received for publication October 31, 2000. Accepted February 2, 2001 


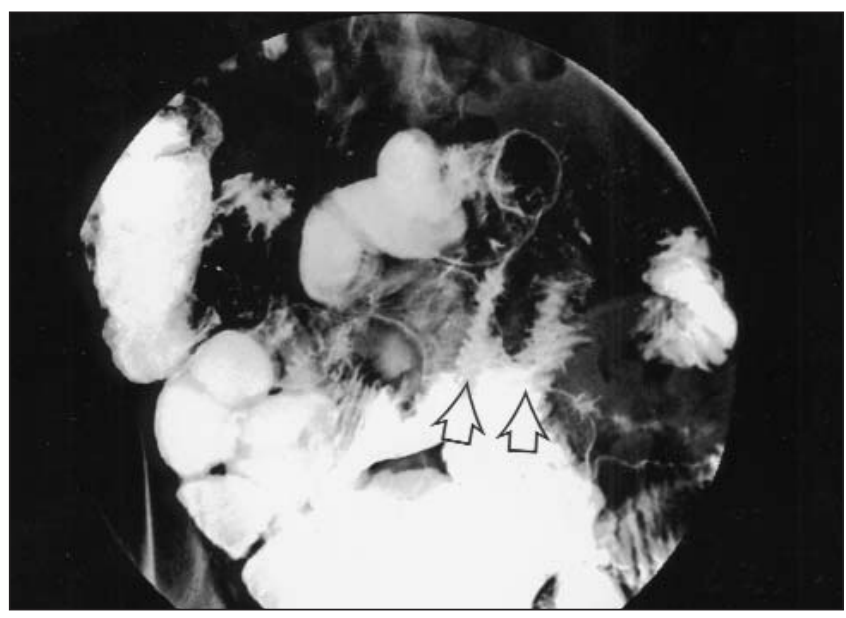

Figure 1) Standard small bowel follow-through demonstrating dilation of the proximal ileal loops with focal areas of narrowing with associated edema (open arrows)

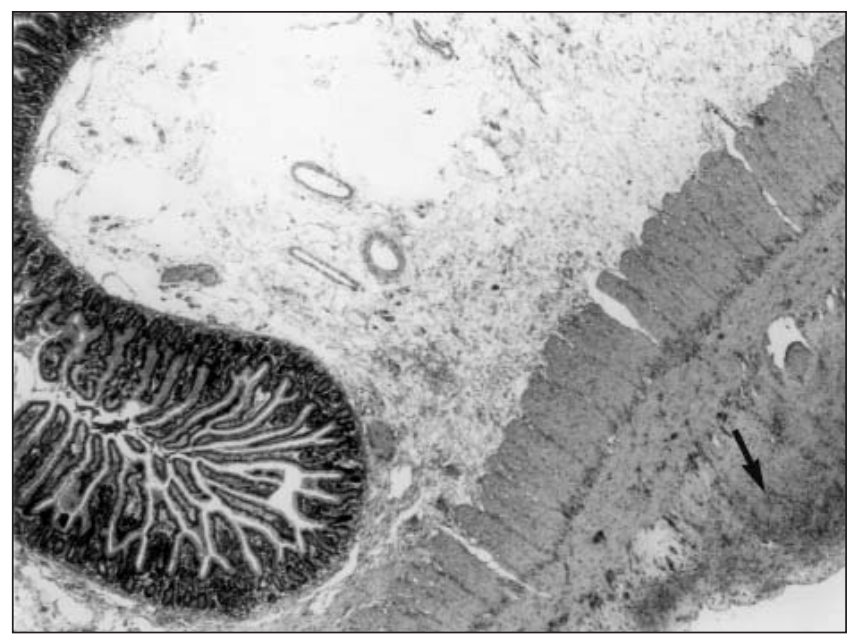

Figure 2) Sclerosing peritonitis involving the small bowel with fibrosis and thickening of serosa and sparing the muscularis propria (arrow) (hematoxylin and eosin stain, original magnification $\times 10$ )

remainder of the examination was unremarkable. Results of initial testing of complete blood count, electrolytes and lipase, and urinalysis were normal. Chest and abdominal $\mathrm{x}$-rays were unremarkable.

Given the severity of pain and localized right lower quadrant peritonitis, a decision was made to proceed to laparotomy, with a tentative diagnosis of acute appendicitis. The possibility of terminal ileal Crohn's disease was also entertained. At laparotomy, it was noted that the base of the appendix was thickened; however, there was no evidence of perforation or abscess. The distal terminal ileum was said to be normal. The appendix was removed, and the patient returned to the ward to recover. Postoperatively, he continued to experience significant right lower quadrant pain for which he required frequent intravenous narcotics. Pathological examination of the excised appendix did not reveal any abnormality. On day 4 of hospitalization, he underwent a small bowel follow-through, which showed

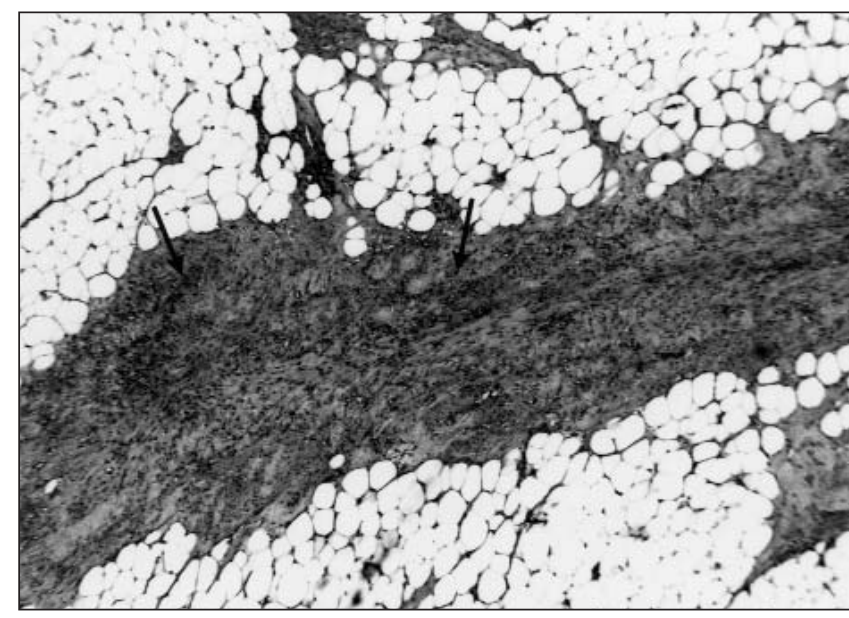

Figure 3) Retractile mesenteritis involving the small intestinal mesentery; note the thickened band of proliferating fibroblasts and collagen in mesenteric fat (arrows) (hematoxylin and eosin stain, original magnification $\times 40$ )

dilation of the proximal ileal loops with focal areas of narrowing and associated edema (Figure 1). Computed tomography scan with intravenous and oral contrast demonstrated a thickened loop of bowel in the proximal ileum. In light of the patient's ongoing severe abdominal pain and significant radiological abnormalities, an exploratory laparotomy was performed. The operative findings were suggestive of marked inflammation, and thickening at the junction of the mesentery and the distal $150 \mathrm{~cm}$ of the ileum. The ileum was dilated. The mesenteric root was grossly normal. Many loops of small bowel were firmly adherent to each other. Given these findings, a partial ileal resection was performed, and a defunctioning ileostomy was created. Pathological examination of the resected portion of ileum revealed thickened, palpable nodularities in the mesentery and on the serosal surface of the bowel. Microscopic examination showed extensive thickening and fibrosis of the serosal surface of the ileum (Figure 2). Proliferating fibroblasts and collagen, arranged in thickened bands, were noted in the small intestinal mesentery (Figure 3). Postoperatively, the patient was started on a course of prednisone $(1 \mathrm{mg} / \mathrm{kg} / \mathrm{day})$ and azathioprine $(1 \mathrm{mg} / \mathrm{kg} / \mathrm{day})$. He began to improve clinically and was discharged.

Five months later, he presented for closure of the ileostomy. Surprisingly, no gross disease was apparent in the mesentery or small intestine, even at the distal $150 \mathrm{~cm}$ of ileum, which had been previously affected. A functional end to end anastamosis was successfully performed. His immunosuppressants were tapered and were discontinued after a five-month course. After nine months of follow-up, he remains well without therapy.

\section{DISCUSSION}

In this report, a young patient with sclerosing mesenteritis responded well to a treatment regimen of corticosteroids, azathioprine and surgery. Sclerosing mesenteritis is an extremely uncommon condition with an often nonspecific presentation, making it a difficult and challenging diagno- 
sis. Either sex may be affected, although there is a slight male preponderance (1.9:1). Caucasians are more commonly affected. Cases have been described in almost all age groups (range five years to 87 years). The etiology of the disease is unknown. However, some have postulated an association with mesenteric panniculitis, in which chronic inflammation may lead to progressive mesenteric fibrosis. Initial mesenteric damage may be a result of trauma, infection, autoimmune disease, or thermal, chemical or other injury. The small bowel mesentery is most commonly involved; however, there are reports of colonic mesentery involvement (2). Isolated or multiple rubbery nodules are often present in the mesentery. Diffuse mesenteric thickening may also be noted. The microscopic appearance may vary from a predominantly acute inflammatory reaction, including fat necrosis and inflammatory infiltrate, to a more chronic fibrotic phase (3). The natural history is usually one of progressive fibrosis and retraction, leading to bowel obstruction or, less commonly, mesenteric ischemia (4).

The clinical presentation is varied; patients may be asymptomatic in up to one-third of cases. Presentations have included abdominal pain, bowel obstruction, palpable masses, fever and even malabsorption in one report $(5,6)$. Laboratory investigations generally are not helpful. Barium studies provide nonspecific information, as obtained in our case. Computed tomography or magnetic resonance imaging may assist in identifying masses within the mesentery. The definitive diagnosis is made histologically.

The treatment of this condition is controversial. Given the rarity of disease, only anecdotal reports can be used to guide potential treatment. Some authors have used corticosteroids, particularly where the inflammatory component is significant. Corticosteroids have been shown to be useful in retroperitoneal fibrosis and, therefore, may also affect the fibrotic component of the disease process (7). One author reported the successful use of a 1.5-year course of tapering azathioprine $(1 \mathrm{mg} / \mathrm{kg} /$ day $)$ and a three-year tapering course of prednisone $(0.5 \mathrm{mg} / \mathrm{kg} /$ day $)$ after initial surgery (4). Our case report clearly is in agreement with these findings. We have demonstrated clinical improvement and gross pathological improvement with a shorter course of this regimen.
Other treatment approaches have included the use of tamoxifen, reported in an human immunodeficiency viruspositive patient, and the use of cyclophosphamide $(8,9)$. The combination of colchicine with corticosteroids has also been reported to be of benefit (10). Finally, oral progesterone has been suggested as an alternative to more traditional immunosuppressant therapy (11). Surgery may be necessary to correct bowel, ureteric or vascular obstruction.

Currently, the clinician is faced with a difficult choice in selecting the appropriate treatment for sclerosing mesenteritis. Given the excellent outcome of our patient and others, it is reasonable to consider azathioprine and corticosteroids early in the course of the disease, once the diagnosis is established.

\section{REFERENCES}

1. Kelly JK, Hwang WS. Idiopathic (reactile) mesenteritis and its differential diagnosis. Am J Surg Pathol 1989;13:513-21.

2. Ikoma A, Tanaka K, Komokata T, Ohi Y, Taira A. Reactile mesenteritis of the large bowel: report of a case and review of the literature. Surg Today 1996;26:435-6.

3. Emory TS, Carr NJ, Monihan JM, et al. Sclerosing mesenteritis: A clinicopathologic study of 85 cases. Mod Pathol 1996;9:56A. (Abst)

4. Tytgat GN, Roozendaal K, Winter W, Esseveld MR. Successful treatment of a patient with reactile mesenteritis with prednisone and azathioprine. Gastroenterology 1980;79:352-6.

5. Horing E, Hingerl T, Hens K, von Gaisberg U, Kieninger G. Protein-losing enteropathy: first manifestation of sclerosing mesenteritis. Eur J Gastroenterol Hepatol 1995;7:481-3.

6. Sans M, Varas M, Anglada A, Esperenza Bachs M, Navarro S, Brugues J. Mesenteric panniculitis presenting as fever of unknown origin. Am J Gastroenterol 1995;90:1159-61.

7. Field C, Arnold W, Gloster ES, Sharp G, Redman J. Steroid therapy as treatment for idiopathic fibrosis of the retroperitoneum and mediastinum. Pediatrics 1986;78:936-8.

8. Bush RW, Hammar SP, Rudolph RH. Sclerosing mesenteritis. Response to cyclophosphamide. Arch Intern Med 1986;146:503-5.

9. Venkatramani A, Behling CA, Lychie KD. Sclerosing mesenteritis: an unusual presentation of abdominal pain in an HIV positive patient. Am J Gastroenterol 1997;92:1059-60.

10. Genereu T, Bellin MF, Wechsler B, et al. Demonstration of efficacy combining corticosteroids and colchicine in two patients with idiopathic sclerosing mesenteritis. Dig Dis Sci 1996;41:686-8.

11. Mazure R, Fernandez MP, Niveloni S, et al. Successful treatment of reactile mesenteritis with oral progesterone. Gastroenterology 1998:114:1313-7. 


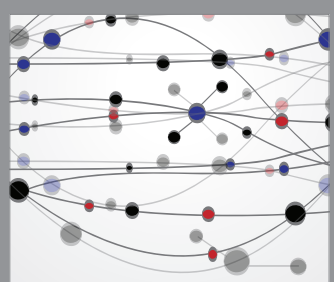

The Scientific World Journal
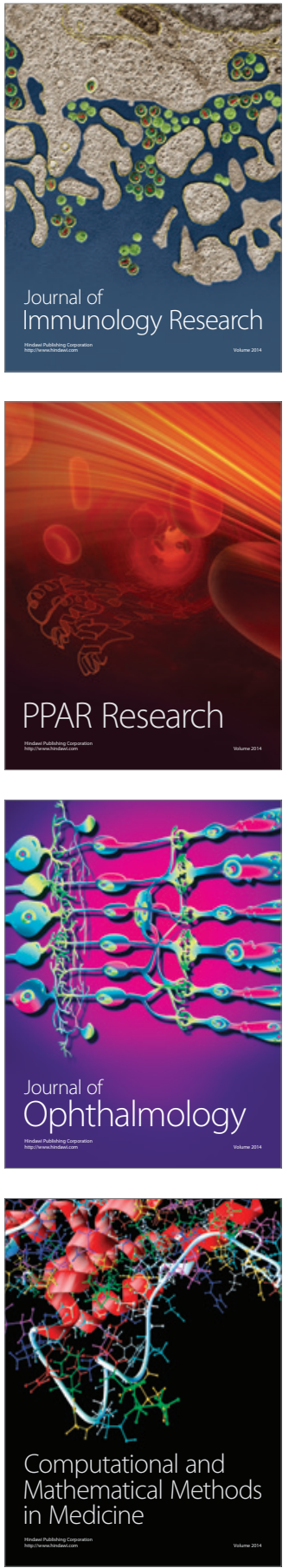

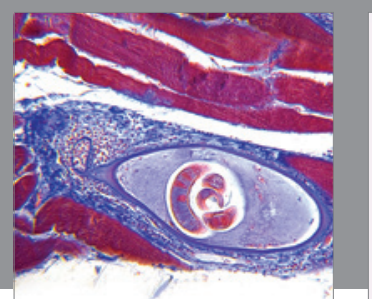

Gastroenterology Research and Practice

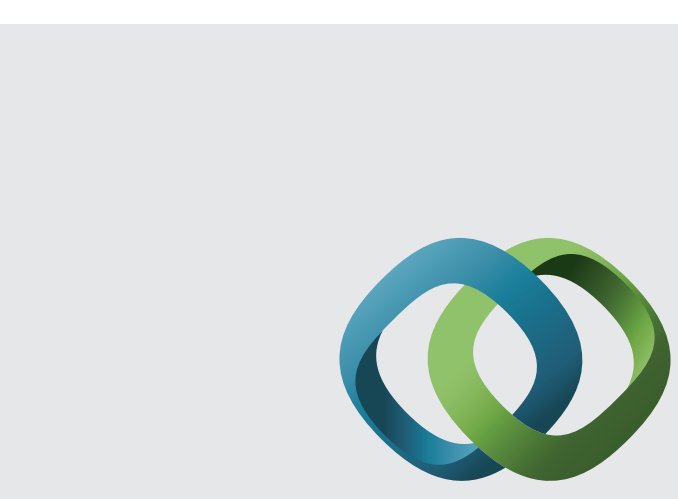

\section{Hindawi}

Submit your manuscripts at

http://www.hindawi.com
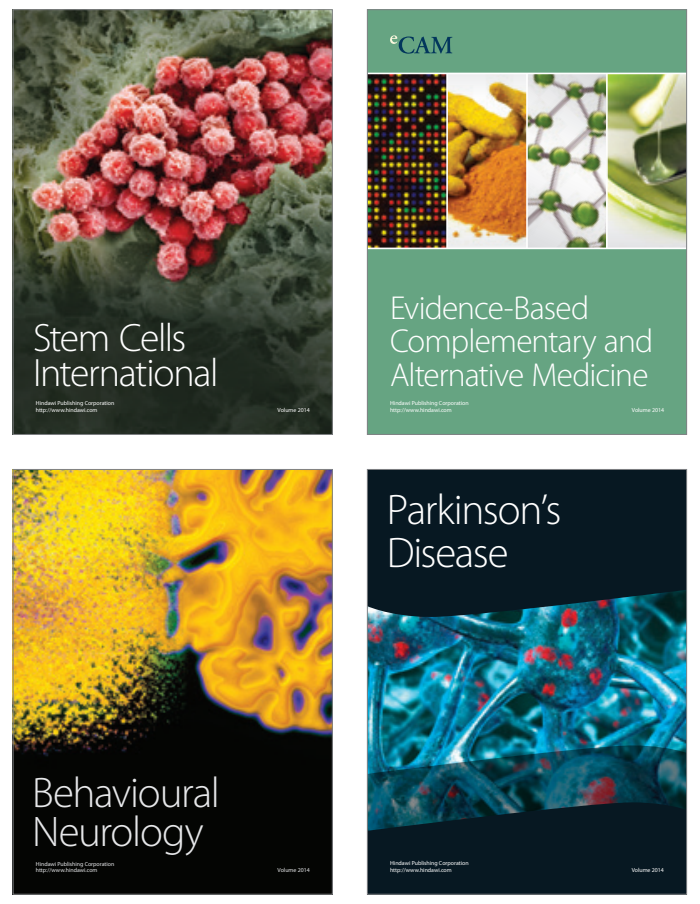
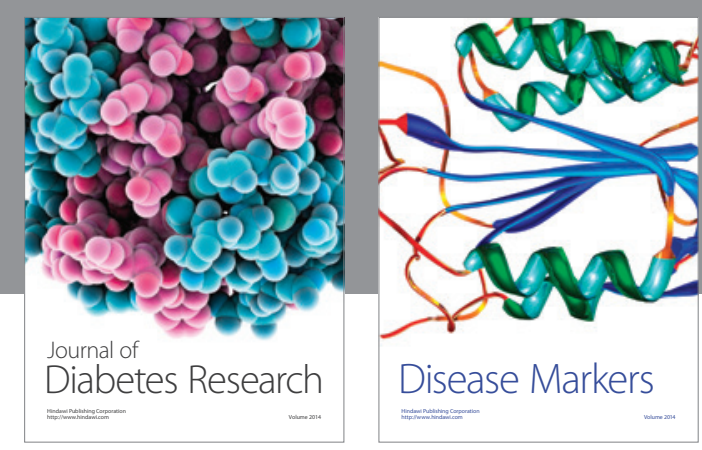

Disease Markers
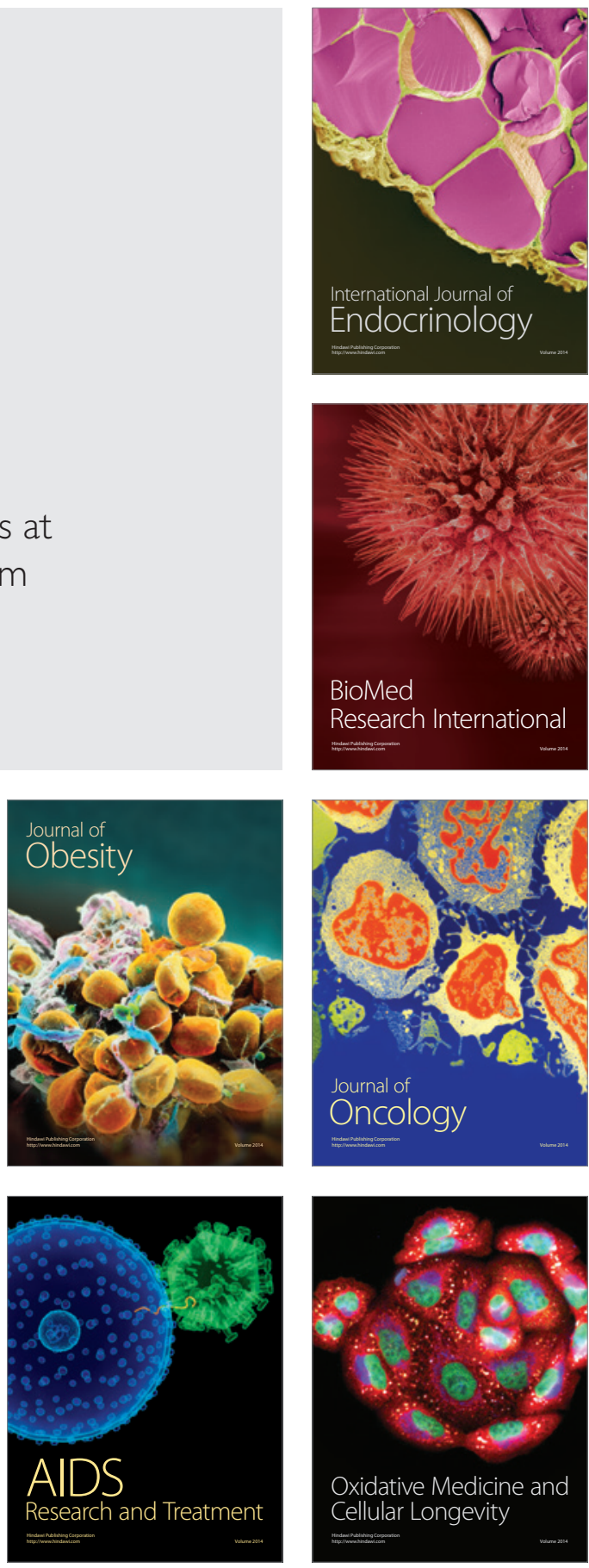